\title{
Evaluation and Assessment of Meteorological Drought by Different Methods in Trarza Region, Mauritania
}

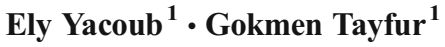

Received: 6 June 2016 / Accepted: 20 September 2016 /

Published online: 10 October 2016

(C) Springer Science+Business Media Dordrecht 2016

\begin{abstract}
Drought Indexes (DIs) are commonly used for assessing the effect of drought such as the duration and severity. In this study, long term precipitation records (monthly recorded for 44 years) in three stations (Boutilimit (station 1), Nouakchott (station 2), and Rosso (station 3)) are employed to investigate the drought characteristics in Trarza region in Mauritania. Six DI methods, namely normal Standardized Precipitation Index (normal-SPI), log normal Standardized Precipitation Index (log-SPI), Standardized Precipitation Index using Gamma distribution (Gamma-SPI), Percent of Normal (PN), the China-Z index (CZI), and Deciles are used for this purpose. The DI methods are based on 1-, 3-, 6-, and 12 month time periods. The results showed that DIs produce almost the same results for the Trarza region. The droughts are detected in the seventies and eighties more than the 1990s. Twelve drought years might be experienced in station 2 and six in stations 1 and 3 in every 44 years, according to reoccurrence probability of the gamma-SPI and log-SPI results. Stations 1 and 3 might experience fewer drought years than station 2, which is located right on the coast. In station 1, which is located inland, when the annual rainfall is less than $123 \mathrm{~mm}$, it is likely that severe drought would occur. This is $63 \mathrm{~mm} /$ year for station 2 and $205 \mathrm{~mm} /$ year for station 3 which is located in the south west on the Senegal River. DI results indicate that the CZI and the gamma-SPI methods make similar predictions and the log-SPI makes extreme drought predictions for the monthly period for all the stations. For longer periods (3-, 6-, and 12 month period), for all the stations, the log-SPI and the gamma-SPI produce similar results, making severe drought predictions while the normal-SPI and the CZI methods predict more wet and fewer drought cases. The logSPI, the gamma-SPI, PN and Deciles were able to capture the historical extreme and severe droughts observed in early 1970s and early 1980s.
\end{abstract}

Ely Yacoub

ely2006123@hotmail.fr

Gokmen Tayfur

gokmentayfur@iyte.edu.tr

1 Department Civil Engineering, Izmir Institute of Technology, Urla, İzmir 35430, Turkey 
Keywords Drought $\cdot$ Trarza Region · Mauritania $\cdot$ SPI $\cdot$ CZI $\cdot$ PN $\cdot$ Deciles $\cdot$ Arid $\cdot$ Precipitation

\section{Introduction}

Drought is the consequence of a natural reduction in the amount of precipitation received over an extended period, such as a season, year and/or decade often accompanied by high temperature, high winds, and low humidity. Drought can affect more people than other natural disasters; the US Federal Emergency Management Agency (FEMA) estimated annual losses of drought at US\$6-8 billion (Wilhite 2000). Since the late 1960s, the Sahel, a semiarid region in West Africa between the Sahara desert and the Guinea coast rainforest had experienced a drought of unprecedented severity in recorded history (Mishra and Singh 2010). The drought had a devastating impact on this ecologically vulnerable region and was a major impetus for the establishment of the United Nations Convention on Combating Desertification and Drought (Zeng 2003). For example, in sub-Saharan Africa, The Office of Foreign Disaster Assistance (OFDA) reported that the droughts of the early to mid-1980s had adversely affected more than 40 million people (Wilhite 1996). The 1991-1992 droughts in southern Africa affected 20 million people and resulted in a deficit of cereal supplies of more than 6.7 million tons (Wilhite 2000).

Some countries across the Sahel (in western Africa) at the end of the drought season heralded a period of steady rainfall. Not so in Mauritania, which is one of the Sahelian countries most affected by drought. In 1983-84, Mauritania was afflicted with its worst drought since the beginning of the 1970s when Mauritania experienced an extended severe drought (Spinage 2012). Households are still struggling to cope with the effects of the drought, which has reduced farmers' crop yield and increased the price of food on local markets. All the regions of the country were affected by the drought in the early 1970s and 1980s including Trarza region, where the flow rate of Senegal River dropped by an average of $75 \%$ between 1970 and 1990. This also caused significant drops in ground water levels in the region (http://pbrnews.com/the-senegal-river-a-history-of-water-control/).

The main source of the groundwater in Mauritania is the Trarza aquifer, which covers about $40,000 \mathrm{~km}^{2}$. The Senegal River is Mauritania's only permanent waterway, which makes the Trarza one the most populated regions in the country. $1086 \mathrm{~km}$ long Senegal River which is located between Mauritania and Senegal flows through a valley up to $19 \mathrm{~km}$ wide (https://en. wikipedia.org/wiki/Senegal_River). It is used for different purposes such as, irrigation, navigation, drinking, and hydropower generation. The water resources in Trarza region support a range of use including urban water supply and agricultural not only in the region but also in the surrounded regions in Mauritania. In October 2010, water from the Senegal River started flowing into Nouakchott's (the capital city) water supply system after the completion of an ambitious hydrological project (Aftout Essahli Drinking Water Supply Project) which was designed to meet the drinking water needs of the city up to 2030. These facts highlight the importance of drought assessment and monitoring for the region.

Assessment of droughts is a primary importance in the planning and management of water resources. In this light, there is the need to investigate droughts in the region historically, in terms of the causes and impacts during their occurrences. Consequently, understanding the different concepts of drought would help in developing models for the droughts. Droughts, unlike other natural disasters creep in slowly and for this reason, it is possible to build mitigation strategies to efficiently combat effects of droughts. Mitigation actions should be 
undertaken in three phases: prior, during and after droughts. This way, not only would the effects be reduced significantly but also at a minimal cost.

DIs are quantitative measures that can characterize drought levels by assimilating data from one or more variables (indicators) such as precipitation and evapotranspiration into a single numerical value. Palmer (1965) first introduced the Palmer Drought Severity Index (PDSI) to define meteorological drought using water balance model in United States. After its application, PDSI became popular immediately and it was the most prominent in United States until Alley (1984) recognized its limitations. In time, other DIs were developed to investigate drought around the world including the widely used PN, Deciles (Gibbs and Maher 1967) and SPI (McKee et al. 1993). These DIs were used to trigger drought relief programs and to quantify deficits in water resources to assess drought severity.

DIs are mostly developed for a specific region. Morid et al. (2006) mentioned that no index is ideal or universally suitable because of the inherent complexity of drought phenomena, and different hydroclimatic and catchment characteristic. After comparing and evaluating the performances of different DIs, Barua et al. (2010) found that Aggregated Drought Index (ADI) was superior to other indexes for drought management within the Yarra River catchment in Australia. In Tehran, the SPI and Effective Drought Index (EDI) were found to be able to detect the onset of drought, its spatial and temporal variation consistently, and it is therefore recommended for operational drought monitoring in the region (Morid et al. 2006). In China, the SPI was found to be an effective index for assessing drought conditions at different time scales (Wu et al. 2001; Yuan and Zhou 2004). However, the choice of indices to monitor the drought in a specific area should be based on the quantity of climate data available and on the ability of the index to consistently detect spatial and temporal variations during a drought event (Morid et al. 2006; Asikoglu and Ciftlik 2015).

The aim of this study is to identify suitable drought index(s) for Trarza region in Mauritania that can be employed for drought assessment within the region. For this purpose, six methods are used, namely normal-SPI, log-SPI, Gamma-SPI, PN, CZI, and Deciles at different time scales. The paper begins with a brief description of the study area and the data followed by the methods. The application is followed by the analysis of the results. The conclusion of the study is presented at the end of the paper.

\section{Study Area and Data}

\subsection{Study Area}

Mauritania is located in western Africa and it is generally composed of the Sahara desert (arid zone) in the north and the Sahel (a semiarid zone) in the south (Fig. 1). The Sahara extends over a large area and it is characterized by an absence of vegetation cover, water scarcity, and sporadic precipitation. The total (actual) renewable surface water resources in Mauritania are estimated at $11.1 \mathrm{~km}^{3} /$ year and the internal renewable surface water resources at $0.1 \mathrm{~km}^{3} /$ year. The hydrographic system is dominated by the Senegal River which runs along the southern border (Fig. 2). In Mauritania, total groundwater resources are estimated at $3.7 \mathrm{~km}^{3}$, which refers to the continuous aquifers only; however the yields of the alluvial groundwater in the wadis and the intermittent aquifer systems have not yet been quantified. The rainy season lasts only 3 months (July-September) with average annual rainfall being $99 \mathrm{~mm}$, but this varies from less than $20 \mathrm{~mm}$ in the north to more than $500 \mathrm{~mm}$ in the south-east, and average minimum and maximum temperatures vary from $16{ }^{\circ} \mathrm{C}$ in January to $36^{\circ} \mathrm{C}$ in June. 


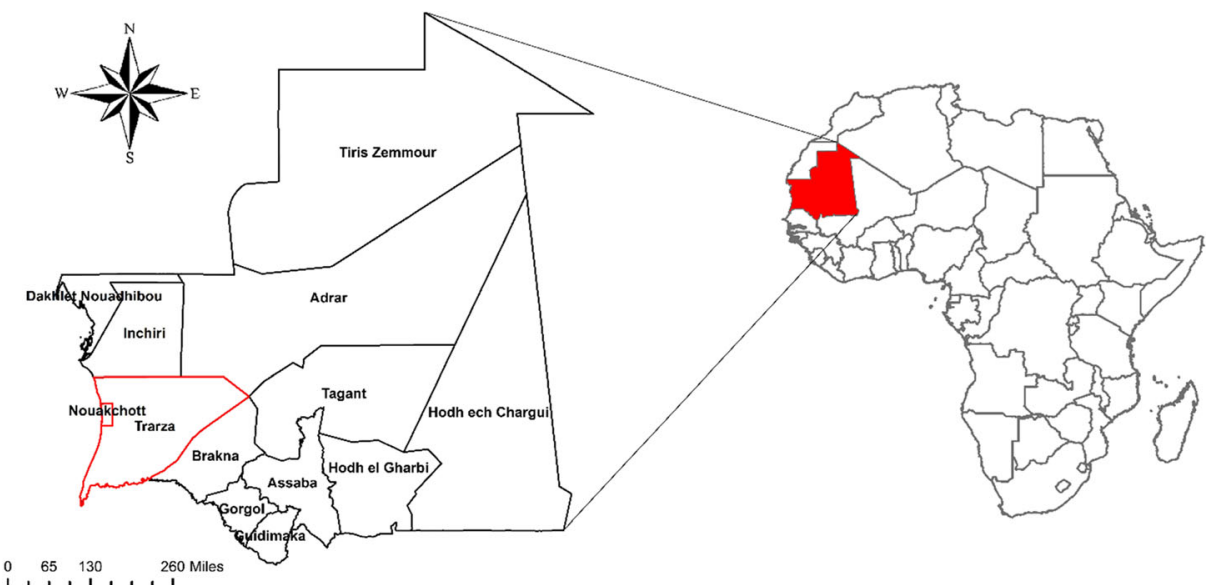

$+1,1,1,1$,

Fig. 1 Mauritania Map

Trarza is a region in southwest Mauritania, it borders the regions of Inchiri and Adrar to the north, Brakna to the east, and the country of Senegal to the south as is shown in the Fig. 2. The water resources in Trarza region support a range of use in Mauritania including urban water supply and agricultural. It borders by the Senegal River which plays a very important role as main surface water source in Mauritania. Trarza has a huge reservoir (La nappe du Trarza) which becomes crucial during drought periods.

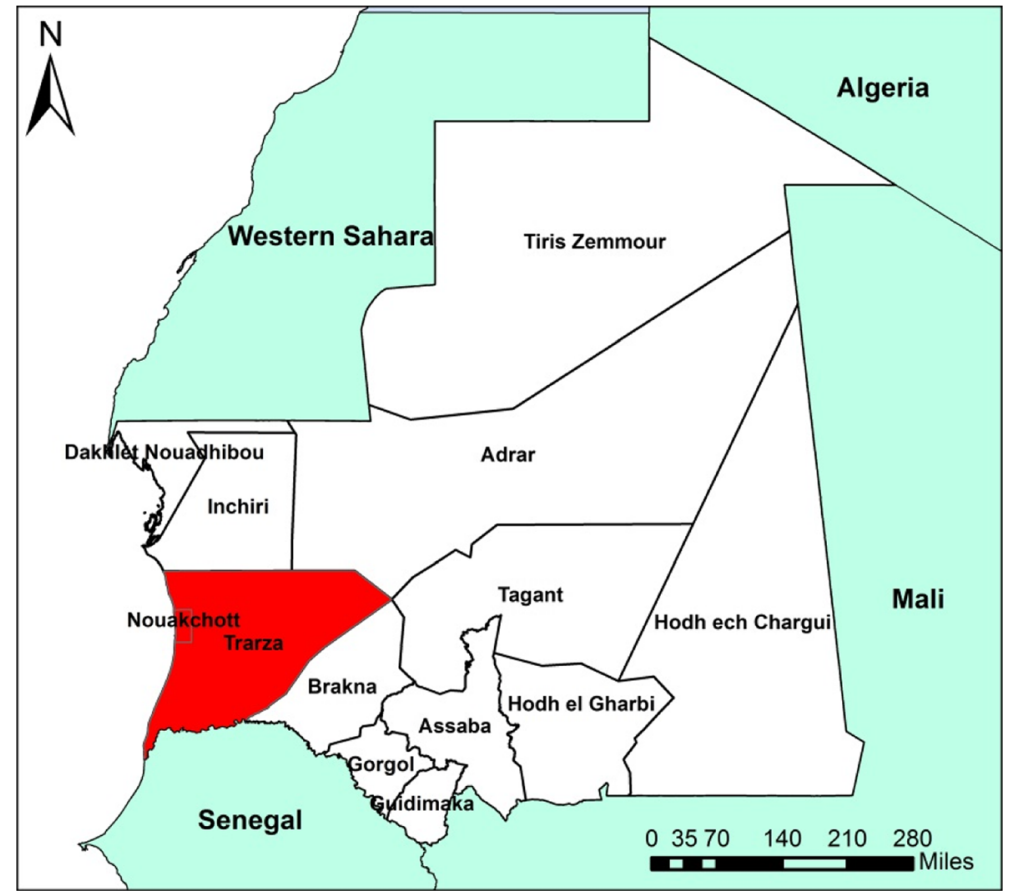

Fig. 2 Trarza Region 


\subsection{Data}

The meteorological observation began in Mauritania in 1905, with the arrival of French. Since then, the activity of observing the weather and climate continues to grow through a meteorological observation network consisting of 18 synoptic stations including 4 stations of marine observations and more than 600 rainfall stations distributed over the country. Yet, this network is still far from meeting the needs of the country and thus it must be compacted to ensure good coverage of the country which is about 1.03 million $\mathrm{km}^{2}$, in size.

The data used in this study for calculating DIs were collected from the National Office of Meteorology of Mauritania (Office National de la Météorologie). Three rainfall stations, namely Boutilimt (station \#1), Nouakchott (station \#2), and Rosso (station \#3), as shown in Fig. 3, were employed in this study. One station (Nouakchott) is outside the catchment area; however, it was considered in this study since it is very close to the study area. Table 1 summarizes the latitude, longitude and altitude for each station.

The monthly precipitation (rainfall) data from 1970 to 2013 are used in this study. The employed rainfall data for each station are shown in Fig. 4. As seen, maximum annual rainfall reaches $311 \mathrm{~mm}$ in 2003 and $226 \mathrm{~mm}$ in 1995 in Stations 1 and 2, respectively while Station 3, which is located in the Senegal River Valley region where the rainfall is higher than other regions, behaves differently with maximum rainfall of $477.8 \mathrm{~mm}$ in 2010 . Table 2 summarizes rainfall characteristics for each station.

\section{Methods}

\subsection{Standardized Precipitation Index (SPI)}

The standardized precipitation index (SPI) for any location is calculated, based on the longterm precipitation record for a desired period. This long-term rainfall record is fitted to a

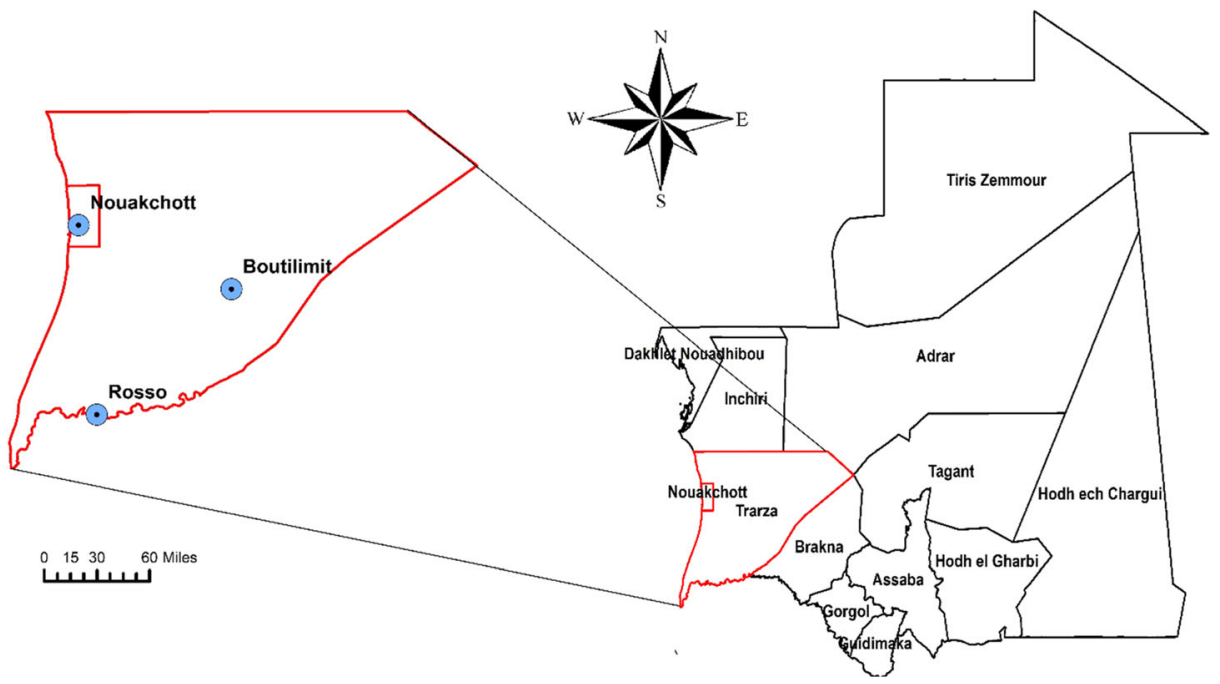

Fig. 3 Rainfall Stations 
Table 1 Location of the meteorological station

\begin{tabular}{llcr}
\hline Station & Latitude & Longitude & Altitude (m) \\
\hline Boutilimt (station \#1) & 17.54 & -14.69 & 48.59 \\
Nouakchott (station \#2) & 18.07 & -15.95 & 4.44 \\
Rosso (station \#3) & 16.51 & -15.95 & 6.26 \\
\hline
\end{tabular}

probability distribution, which is then transformed to a normal distribution using an equalprobability transformation so that the mean SPI for the location and desired period is zero (McKee et al. 1993) and as such, values above zero indicate wet periods and values below zero indicate dry periods.

In 1993 researchers at Colorado State University proposed the SPI to be a relatively simple for the purpose of defining and monitoring drought (Hayes et al. 1999). The SPI has several characteristics that are effectivity for drought monitoring, and its simplicity and temporal flexibility, allowing its application for water resources in all timescales (Hayes et al. 1999).

(a)

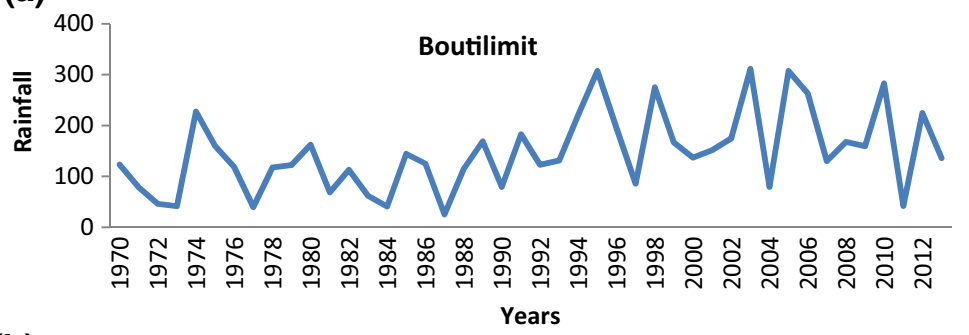

(b)

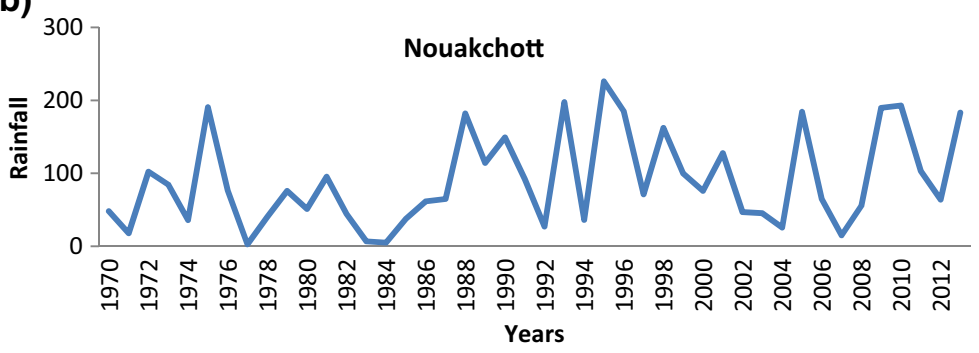

(c)

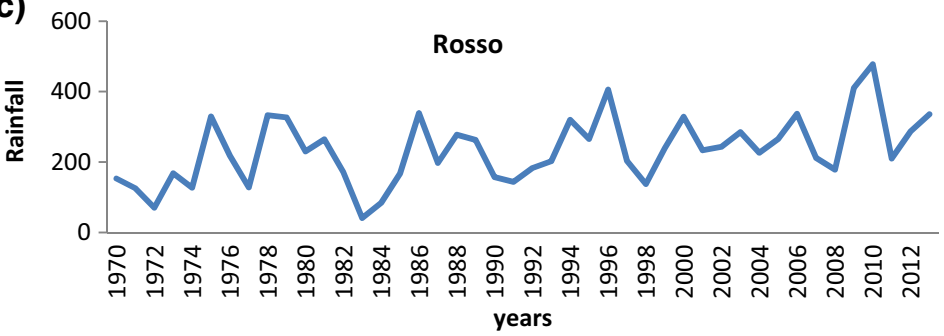

Fig. 4 The rainfall in the 3 Stations (Boutilimit (a), Nouakchott (b) and Rosso (c)) 
Table 2 Annual Rainfall Characteristics

\begin{tabular}{llll}
\hline Rainfall characteristics & Boutilimit & Nouakchott & Rosso \\
\hline Mean & 146.22 & 89.97 & 234.12 \\
Standard Error & 11.69 & 9.55 & 14.19 \\
Median & 133.75 & 73.5 & 228.15 \\
Mode & 307.2 & 75.9 & 265.5 \\
Standard Deviation & 77.56 & 63.37 & 94.12 \\
Sample Variance & 6016.17 & 4016.02 & 8860.44 \\
Kurtosis & -0.27 & -0.83 & -0.0075 \\
Skewness & 0.57 & 0.62 & 0.30 \\
Range & 286.1 & 223.2 & 436.7 \\
Minimum & 25.3 & 2.7 & 41.1 \\
Maximum & 311.4 & 225.9 & 477.8 \\
Confidence & & & 28.61 \\
Level (95.0 \%) & 23.58 & 19.26 & \\
\hline
\end{tabular}

The use of different types of statistical distribution affects the SPI values as the SPI is based on the fitting of a distribution to precipitation series. Some of the commonly applied distributions include gamma distribution (Edwards 1997) and Pearson Type III distribution (Guttman 1999). Normal, log-normal, extreme value, and exponential distributions are widely applied to simulations of precipitation distributions (Lloyd-Hughes and Saunders 2002, Madsen et al. 1998; Thom 1966; Todorovic and Woolhiser 1976). In this study, three types of probability distribution of normal, log-normal, and Gamma are employed.

\subsubsection{Normal-SPI}

It may be sometimes more effective, at the computational level, to standardize the data directly from a fitted normal distribution where possible. The normal-SPI is computed as follows (Cacciamani et al. 2007):

$$
S P I=z=\frac{x-\hat{\mu}}{\hat{\sigma}}
$$

where, $\mathrm{z}$ is the standardized value, and $\hat{\mu}$ and $\hat{\sigma}$ are the sample estimates of the population mean and standard deviation, respectively.

\subsubsection{Log-Normal SPI}

In common with the gamma distribution, the log-normal distribution is positively skewed and non-negative. It has the benefit of its simplicity since it is just a logarithmic transformation of the data. Log-normal SPI is calculated as follows (Lloyd-Hughes and Saunders 2002):

$$
S P I=z=\frac{\ln (x)-\hat{\mu}}{\hat{\sigma}}
$$

The drought classifications for the z-score (SPI) are summarized in Table 3. 
Table 3 SPI Drought Classification (Barua et al. 2010)

\begin{tabular}{ll}
\hline SPI value $(z-s c o r e)$ & Category \\
\hline 2.00 or more & Extremely wet \\
1.50 to 1.99 & very wet \\
1.00 to 1.49 & Moderately wet \\
0.99 to -0.99 & Near normal \\
-1.00 to -1.49 & Moderate drought \\
-1.5 to -1.99 & Severe drought \\
-2 or less & Extreme drought \\
\hline
\end{tabular}

\subsubsection{Gamma-SPI}

In most cases, Gamma distribution is the best model for observational precipitation data. The density probability function for the Gamma distribution is expressed as (Sonmez et al. 2005):

$$
f(x, \alpha, \beta)=\frac{1}{\beta^{\alpha} \Gamma(\alpha)} x^{\alpha-1} e^{x / \beta} \text { for } x, \alpha, \beta>0
$$

where $\alpha$ and $\beta$ are the shape and scale parameters, respectively. $X$ is the rainfall amount and $\Gamma(\alpha)$ is the Gamma function defined by the integral (Gasiorek and Musiał 2015) :

$$
\Gamma(x)=\lim _{n \rightarrow \infty} \prod_{v=0}^{n-1} \frac{n ! n^{y-1}}{y+v} \equiv \int_{0}^{\infty} y^{\alpha-1} e^{-y} d y
$$

The maximum likelihood method is used to estimate the optimal values of the parameters $\alpha$ and $\beta$ by using Eqs (5-6) (Barua et al. 2010) as:

$$
\begin{gathered}
\hat{\alpha}=\frac{1}{4 A}\left(1+\sqrt{1+\frac{44}{3}}\right) \\
\hat{\beta}=\frac{\bar{x}}{\hat{\alpha}}
\end{gathered}
$$

for n number of observations (Barua et al. 2010),

$$
A=\ln (\bar{x})-\frac{\sum \ln (x)}{n}
$$


The resulting parameters $\hat{\alpha}$ and $\hat{\beta}$ are then used to cumulative probability for nonzero rainfalls by using the Equ. 8 (Barua et al. 2010) as follows:

$$
F(x)=\int_{0}^{x} f(x) d x=\frac{1}{\hat{\beta}^{\hat{\alpha}}} \int_{0}^{x} x^{\hat{\alpha}-1} e^{-x / \hat{\beta}} d x
$$

Equation 8 can also be expressed as (Barua et al. 2010):

$$
F(x)=\frac{1}{\Gamma(\hat{\alpha})} \int_{0}^{x} t^{\hat{\alpha}-1} e^{-t} d x
$$

where $t=X / \hat{\beta}$. Since the gamma function is undefined for $X=0$ and precipitation may contain zeros, the calculations of probability of zero and non-zero becomes (Lloyd-Hughes and Saunders 2002)

$$
H(x)=q+(1-q) F(x)
$$

where, $\mathrm{q}$ is the probability of zero rainfall when $\mathrm{m}$ is the number of zeros in a precipitation time series, then $\mathrm{q}$ is estimated by $\mathrm{m} / \mathrm{n}$. The cumulative probability, $\mathrm{H}(\mathrm{x})$ is then transformed to the standard standardized normal distribution so that the SPI mean $(Z)$ and the variance become 0 and 1, respectively. Using an approximation provided by Abramowitz and Stegun (1965), which converts cumulative probability into the standard normal random variable, called z:

$$
\begin{gathered}
S P I=z=-\left(k-\frac{c_{0}+c_{1} k+c_{2} k^{2}}{1+d_{1} k+d_{2} k^{2}+d_{3} k^{3}}\right) \\
\text { when } k=\sqrt{\ln \left\{\frac{1}{[H(x)]^{2}}\right\}} \text { for } 0<\mathrm{H}(\mathrm{x}) \leq 0.5 \\
S P I=z=+\left(k-\frac{c_{0}+c_{1} k+c_{2} k^{2}}{1+d_{1} k+d_{2} k^{2}+d_{3} k^{3}}\right) \\
\text { when } k=\sqrt{\ln \left\{\frac{1}{[1-H(x)]^{2}}\right\} \text { for } 0.5<\mathrm{H}(\mathrm{x}) \leq 1}
\end{gathered}
$$

where, $c_{0}=2.515517, c_{1}=0.802853, c_{2}=0.010328, d_{1}=1.432788, d_{2}=0.189369$, and $d_{3}=0.001308$. The SPI threshold range that is used to define severity of the drought is presented in Table 3.

\subsection{Percent of Normal}

The Percent of Normal (PN) is a meteorological drought index, which is calculated by dividing actual precipitation by normal precipitation - typically considered to be a 30-year mean - and multiplying by $100 \%$ (Hayes 2006a). PN Drought classification is presented in Table 4. 
Table 4 PN Drought Classification (Barua et al. 2010)

Threshold range

Drought classification

$180 \%$ or more of normal rainfall

Extremely wet

$161 \%$ to $180 \%$ of normal rainfall

Very wet

$121 \%$ to $160 \%$ of normal rainfall

Moderately wet

$81 \%$ to $120 \%$ of normal rainfall

Near normal

$41 \%$ to $80 \%$ of normal rainfall

Moderately drought

$21 \%$ to $40 \%$ of normal rainfall

Severe drought

$20 \%$ or less of normal rainfall

Extremely drought

The time scale of the analysis can vary from a single month to a year. The percent of normal is highly transparent, which makes it favorable for communicating drought levels to the public (Keyantash and Dracup 2002). The use of PN implies a normal distribution which considered the mean and the median to be the same (Hayes 2003), which is not necessarily true. Therefore, mitigating the risks of drought based on the departures from normal is not a useful decision-making tool when used alone (Hayes 2006b).

\subsection{China-Z Index (CZI)}

The CZI is a drought index that was introduced to the National Meteorological Center of China (NMCC) in early 1990s. The CSI is calculated as (Ju et al. 1997):

$$
\begin{gathered}
z_{i}=\frac{6}{C_{s i}}\left(\frac{C_{s i}}{2} \varphi_{i}+1\right)^{1 / 3}-\frac{6}{C_{s i}}+\frac{C_{s i}}{6} \\
C_{s i}=\frac{\sum_{j}^{n}=1\left(x_{i j}-\overline{x_{i}}\right)}{n^{*} \sigma_{i}^{3}} \\
\varphi_{i}=\frac{x_{i}-x_{i}}{\sigma_{i}}
\end{gathered}
$$

Table 5 Deciles Drought Classifications (Gibbs and Maher, 1967, Barua et al. 2010)

Threshold range

Drought classification

Deciles 1-2 (lowest $20 \%$ )

Much below normal

Deciles 3-4 (next lowest $20 \%$ )

Below normal

Deciles 5-6 (middle $20 \%$ )

Near normal

Deciles 7-8 (next highest $20 \%$ )

Above normal

Deciles 9-10 (highest $20 \%$ )

Much above normal 


\section{Boutilimit}

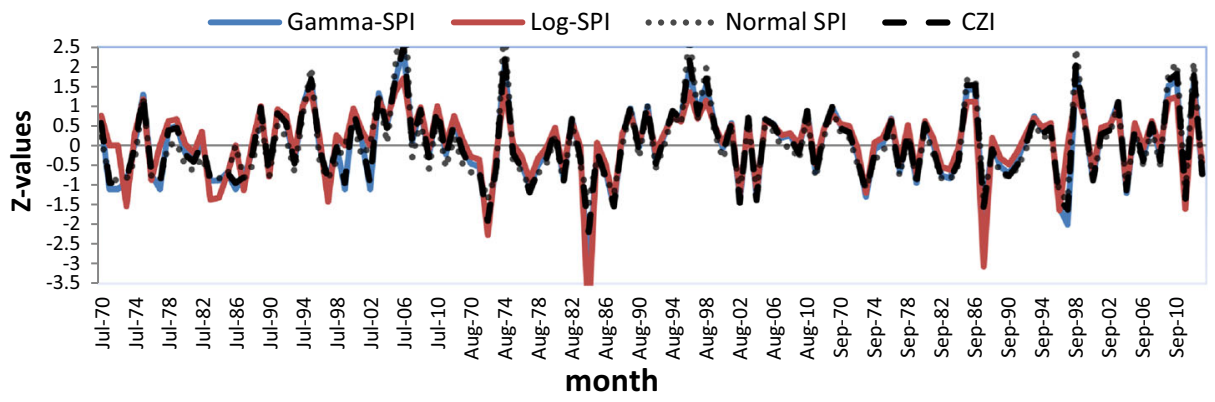

Fig. 5 SPI and CZI results for monthly period for Boutilimit (Station 1)

where $z_{i}$ is the CZI, $i$ is the time scale interest, $C_{s i}$ is the coefficient of skewness and $n$ is the total number of years in the record, $\varphi_{i}$ is a standard deviation, $x_{i}$ is a precipitation, $\bar{x}_{i}$ is the average and $\sigma_{i}$ is the standard division.

\subsection{Deciles}

The method of deciles is based on dividing the distribution of monthly record precipitation into 10 parts (or deciles) (Tsakiris et al. 2007). It was developed by Gibbs and Maher (1967) to avoid some of the weaknesses within the "percent of normal" approach. In calculating deciles, long-term monthly rainfall records are first ranked from highest to lowest to construct a cumulative frequency distribution (Barua et al. 2010). The threshold ranges of deciles used to define drought conditions are presented in Table 5.

\section{Application}

Forty four years precipitation records, collected from 3 weather stations are used to apply 6 DI methods for the assessment of drought in Trarza region for periods of 1, 3, 6, and 12 months. Since the rainy season is July-September, only this 3 months period was considered in the analysis for monthly and 3 months analysis.

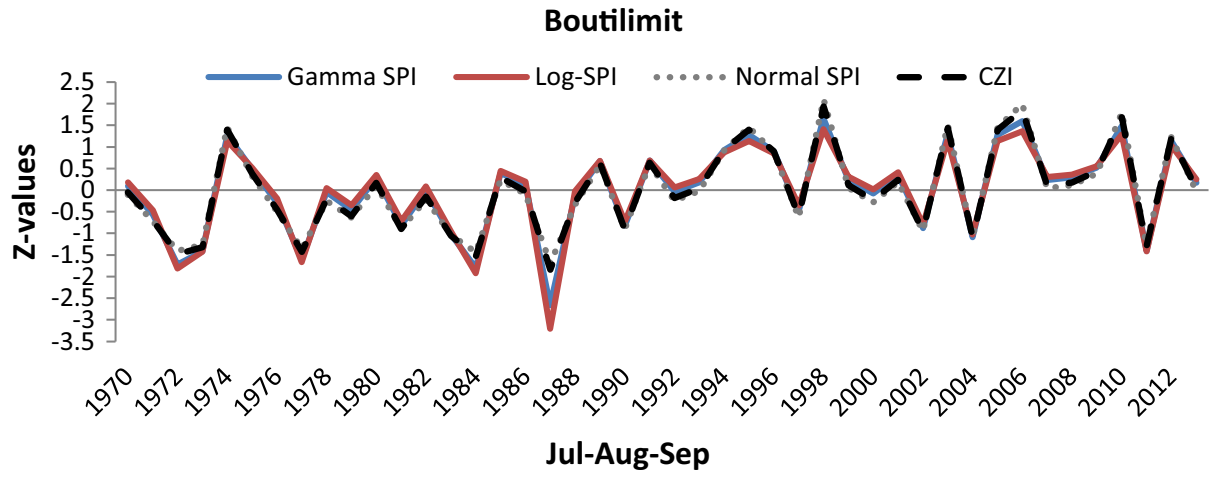

Fig. 6 SPI and CZI results for 3-months period for Boutilimit (Station 1) 


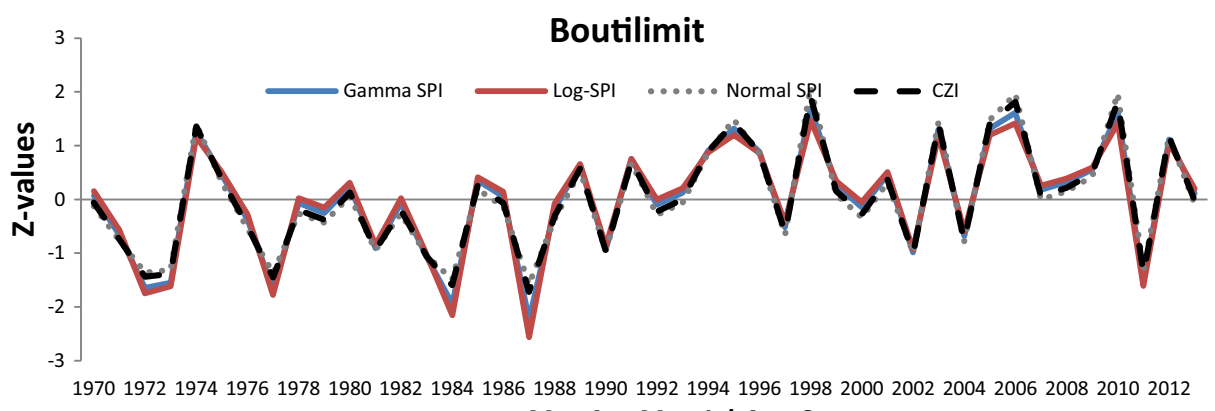

Mar-Avr-May-Jul-Aug-Sep

Fig. 7 SPI and CZI results for 6-months period for Boutilimit (Station 1)

\subsection{Results for Boutilimit (Station 1)}

Figures 5, 6, 7, and 8 presents SPI and CZI results for periods of 1, 3, 6, and 12 months, respectively while Table 6 summarizes the deciles results. Figure 5 presents monthly period DI results for station 1. All DI methods produced almost the same results. The CZI and the gamma-SPI methods made more similar predictions for 1-month period. These method tend to make less drought and more wet conditions. The log-SPI makes extreme drought predictions, like the ones in 1984 and in 1987 (Fig. 5). In the case of 3-months period, all the methods produced the same predictions. Here, the log-SPI and the gamma-SPI showed more similar performance in terms of prediction of the severe drought condition in 1987 (Fig. 6). The normal-SPI and the CZI tend to make wet and less drought conditions (Fig. 6). These similar results are obtained for the case of 6-months period (Fig. 7) and the annual (12 months period) drought predictions (Fig. 8). According to Fig. 8, in 1972-1973, 1977, 1984, and 1987 there occurred severe/extreme drought conditions in Boutilimit station.

Figures 5, 6, 7, and 8 show that extreme drought was detected in 1987 while distinct drought events occurred in the years 1973, 1977, 1984, and 2011. The long dry periods were detected from 1970 to 1974 and 1982 to 1985.

According to decile results in Table 6, when annual rainfall is less than $133.8 \mathrm{~mm}$ drought conditions occur. Severe drought conditions would occur when annual rainfall is less than $80 \mathrm{~mm}$ (Table 6).

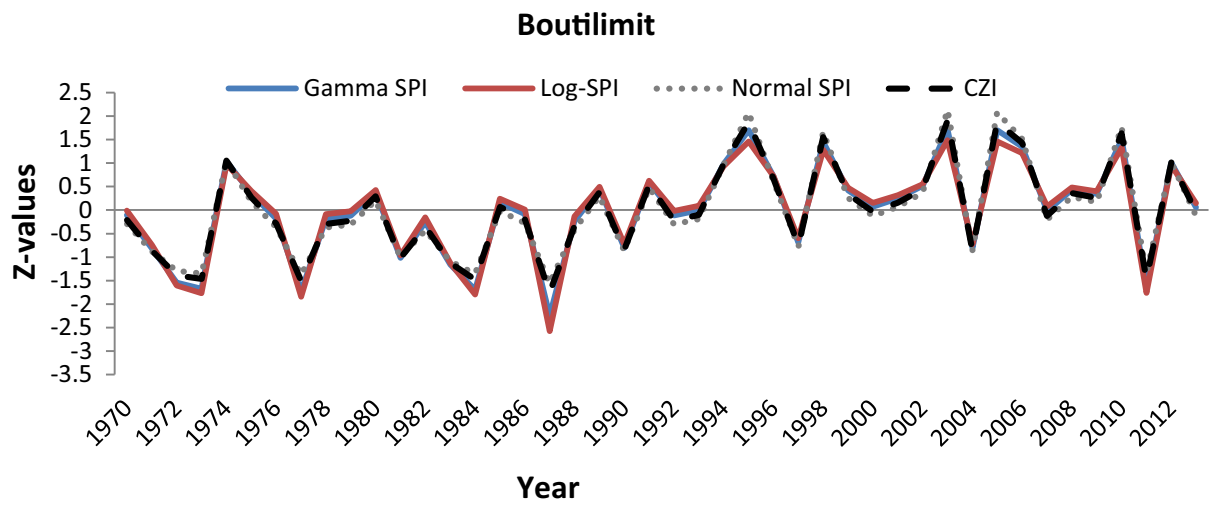

Fig. 8 SPI and CZI results for 12-months period for Boutilimit (Station 1) 
Table 6 Deciles result for Boutilimit (Station 1)

\begin{tabular}{ll}
\hline Annuals Rainfall Values $(\mathrm{mm})$ & Classification \\
\hline $43.1-78.9$ & Much below normal \\
$114.3-123.1$ & Below normal \\
$133.8-157.9$ & Near normal \\
$167.8-205.2$ & Above normal \\
$271.5-311.4$ & Much above normal \\
\hline
\end{tabular}

\subsection{Station of Nouakchott (Station 2)}

Figures 9, 10, 11, and 12 present the SPI and CZI results for periods of 1, 3, 6, and 12 months, respectively while Table 7 summarizes the decile results for Nouakchott station. For monthly period, the CZI and the gamma-SPI show similar behavior while the log-SPI tend to produce severe drought predictions (Fig. 9). The results of DIs for 3-, 6-, and 12-months periods are similar. The normal-SPI and the CZI make fewer drought predictions while the gamma-SPI and the log-SPI make severe drought predictions, such as the ones in 1977 and 1984 (Figs. 10, 11, and 12).

Figures 9, 10, 11, and 12 show that drought appeared more frequently and intensity in this station, compared to the other stations during 44 years. Years; 1977 and 1987 were the worse in term of intensity (extremely droughts), however drought occurred by different intensity in the years; 1971, 1974, 1992, 1994, 2004 and 2007. The driest periods detected by DIs were the periods of 1970-1972, 1982-1986, and 2002-2005.

According to Table 7, in station of Nouakchott, less than $73.5 \mathrm{~mm} /$ year rainfall is considered as drought according. Less than $63 \mathrm{~mm} /$ year and less than $37 \mathrm{~mm} /$ year rainfall are considered severe and extreme drought conditions, respectively (Table 7).

\subsection{Station of Rosso (Station3)}

Figures 13, 14, 15, and 16 presents SPI and CZI results for periods of 1, 3, 6, and 12 months, respectively while Table 8 summarizes the deciles results. The CZI and the gamma-SPI tend to predict more wet and fewer drought conditions and the log-SPI predicts more severe drought

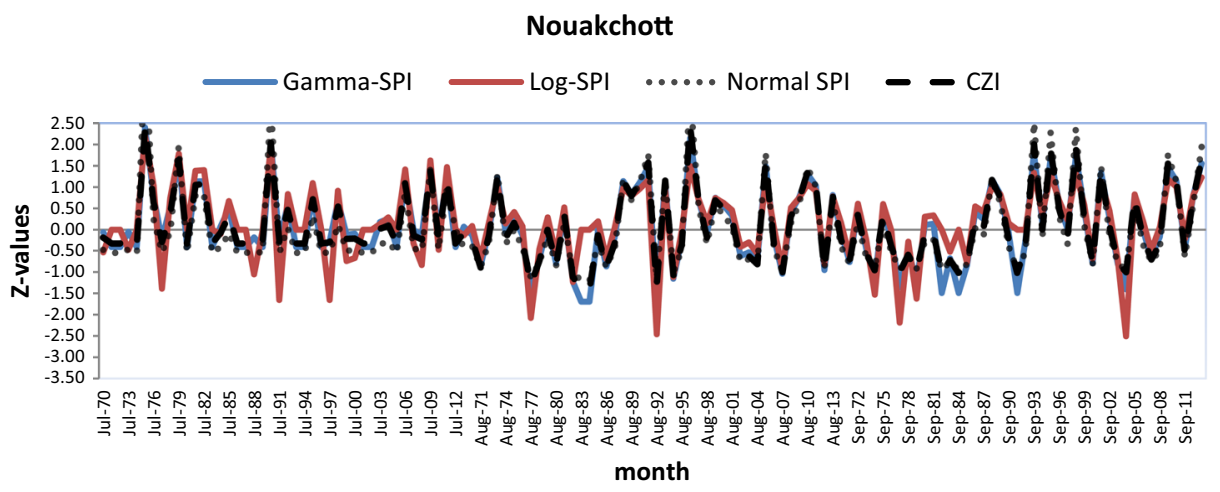

Fig. 9 SPI and CZI results for monthly period for Nouakchott (Station 2) 


\section{Nouakchott}

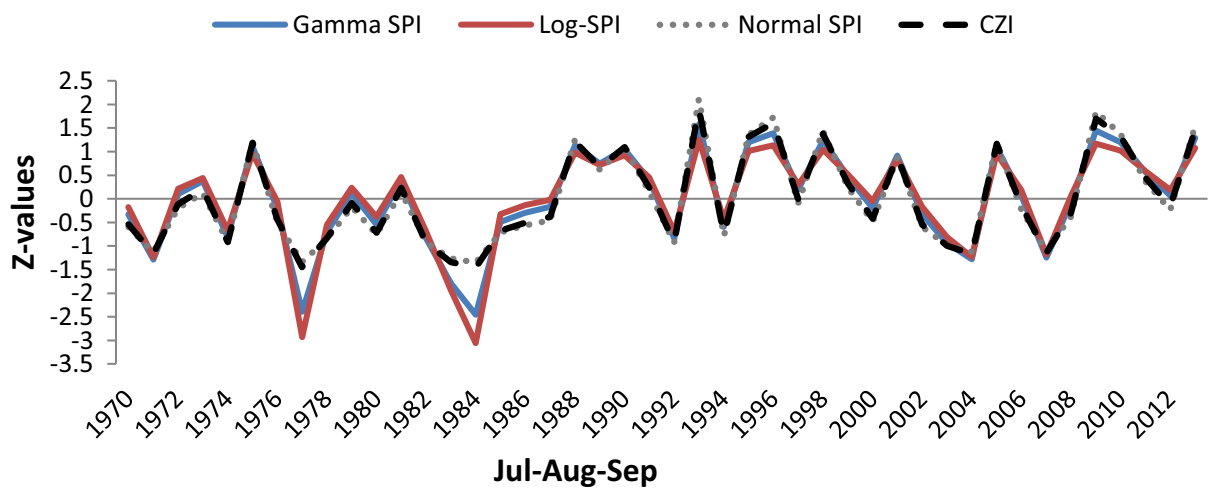

Fig. 10 SPI and CZI results for 3-months period for Nouakchott (Station 2)

conditions such as the ones in August 1971, August 1984, September 1984 and September 1990, in a monthly period analysis (Fig. 13). In the three-month period analysis, the gammaSPI and log-SPI made more drought condition predications such as the ones in 1972, 1983 and 2002 while the normal-SPI and the CZI predicts more wet conditions such as the one in 20092010 period (Fig. 14). The similar result is obtained in the case of 6-month and 12-month periods as well (Figs. 15, 16).

Figures 13, 14, 15, and 16 show that the most effected years by drought are 1972 and 1983 (extremely drought) and drought has also been detected with different intensity in the years 1974, 1977, 1998. The longest dry periods were detected in 1970-1975 and 1982-1985.

As shown in Table 8, less than $243.8 \mathrm{~mm}$ /year rainfall is considered as drought condition. This becomes severe and extreme drought condition when annual rainfall is less than $205 \mathrm{~mm}$ and $155 \mathrm{~mm}$, respectively (Table 8).

\section{Discussions of Results}

The difference between the results produced by the methods (gamma-SPI, Normal-SPI, logSPI, CZI, PN) is due to the ability of the method to fit the probability distribution to the data;

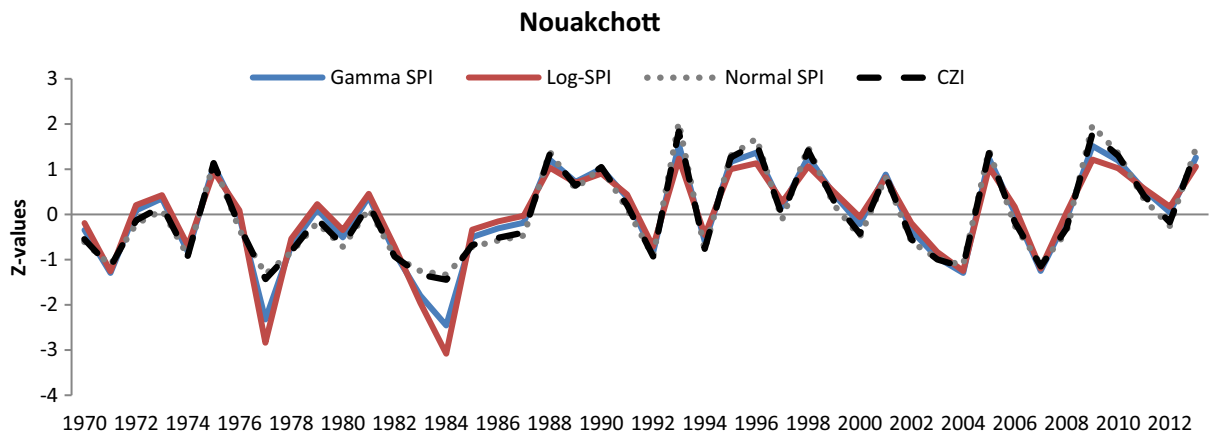

Mar-Avr-May-Jul-Aug-Sep

Fig. 11 SPI and CZI results for 6-months period for Nouakchott (Station 2) 


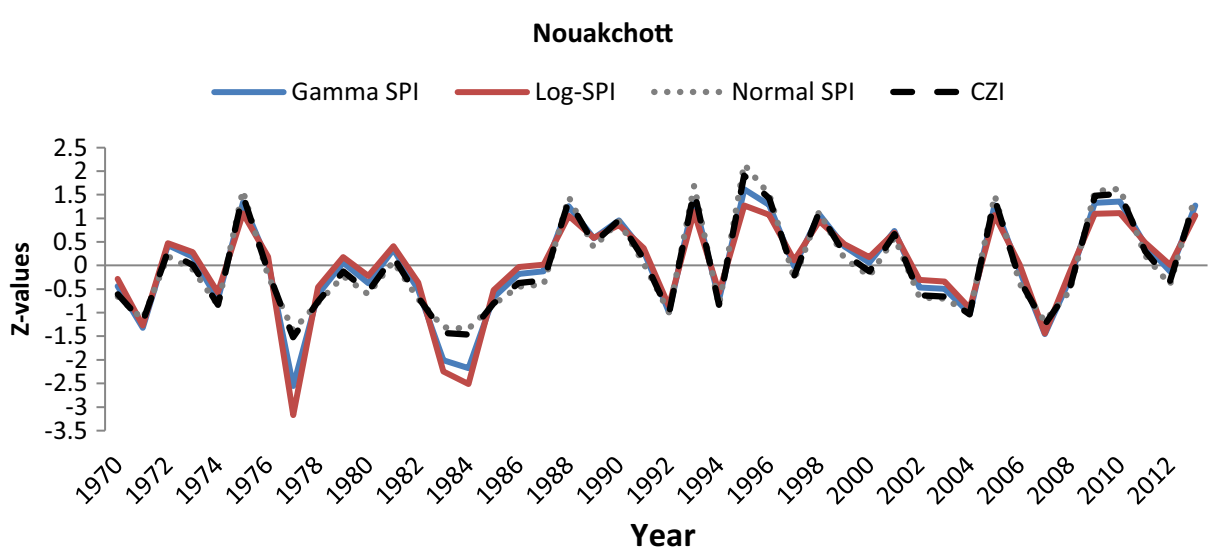

Fig. 12 SPI and CZI results for 12-months period for Nouakchott (Station 2)

the normal-SPI method considers the data is normally distributed, but in fact the data used in this study is not normally distributed. The skewness was found to be $0.57,0.62$ and 0.30 at Boutilimit, Nouakchott and Rosso, respectively (Table 2). The normal-SPI was able to capture the historical droughts recorded in the station of Rosso and this can be explained by the low value of the skewness of 0.3 in this station. Normal-SPI was not able to capture the historical drought recorded in the stations Boutilimit and Nouakchott due to the significant skewness of the data recorded in these stations ( 0.57 and 0.68 , respectively). The log-SPI considers that the data are positively skewed where it matches the data used in the study, and that is why this method was able to capture the historical droughts recorded in the region. Similar to log-SPI, Gamma-SPI was able to capture the drought in the region due to its flexibility to match the data distribution.

Table 9 summarizes the predicted moderate, severe, and extreme drought years by the DI methods for the three stations. PN method results are also presented in Table 9. According to Table 9, PN, the log-SPI, and the gamma-SPI methods captures 1987 as the year of extreme drought, 1972, 1973, 1977, 1984, and 2011 as the years of severe drought and 1983 as the year of moderate drought for Boutilimit station. According to the normal-SPI and the CZI methods, 1987 was the severe drought year for the station 1. The years 1972, 1973, 1977, 1981, 1983, 1984, and 2011 were the moderate drought years for the station 1. These results indicate that the normal-SPI and the CZI tend to make one-step underprediction of the degree of the drought. Also, the results indicate that the PN method tend to increase the number of moderate drought years for the three stations (Table 9).

Table 7 Deciles result for Nouakchott (Station 2)

\begin{tabular}{ll}
\hline Annuals Rainfall Values $(\mathrm{mm})$ & Classification \\
\hline $20.3-37.1$ & Much below normal \\
$46.7-62.7$ & Below normal \\
$73.5-90.5$ & Near normal \\
$104.3-170.2$ & Above normal \\
$188.3-225.9$ & Much above normal \\
\hline
\end{tabular}




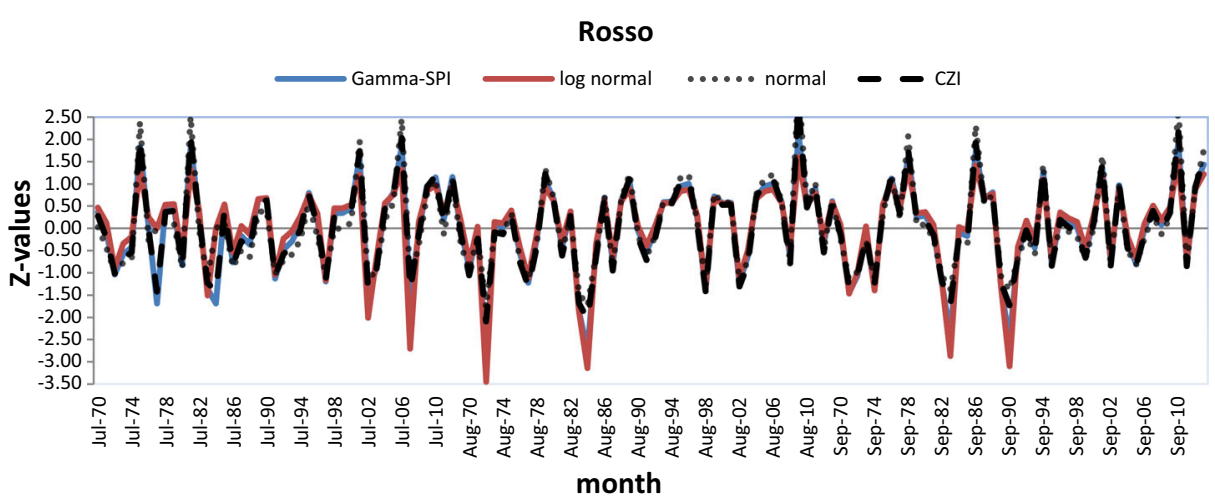

Fig. 13 SPI and CZI results for monthly period for Rosso (Station 3)

1977, 1983 and 1984 were predicted as the extreme drought years for the station 2 by the PN and log-SPI and gamma-SPI methods. By the same methods, 2004 was predicted as the severe drought year for station 2 (Nouakchott). For Rosso station, all the methods indicate that 1983 was the year of extreme drought, 1972, 1984 were the severe drought years and 1971, 1974, and 1977 were the years of moderate drought in the station 3 (Table 9). The normal-SPI and the CZI methods indicated no extreme and severe drought cases for the station 2, unlike the other 4 DI methods (Table 9).

Table 10 summarizes the probability of the drought reoccurrence according to the gammaSPI results. As seen in Table 10, 6 severe/extreme drought years might be experienced in stations 1 and 2 in every 44 years. That means, one in every 7 year period, there could be a severe drought year in these stations. According to Table 10, while stations might experience fewer drought years than the station 2 .

Table 11 summarizes the common years that have experienced drought predicted by the PN method. As seen in Table 11, stations 1 and 3 have experienced almost the same occurrences of droughts, unlike station 2; PN has detected 14 drought years in 44 for the stations 1 and 3, and 22 drought years in 44 years for the station 2. PN has predicted more moderate drought years after 1997 in station 2 than the other stations (Table 9).

\section{Rosso}

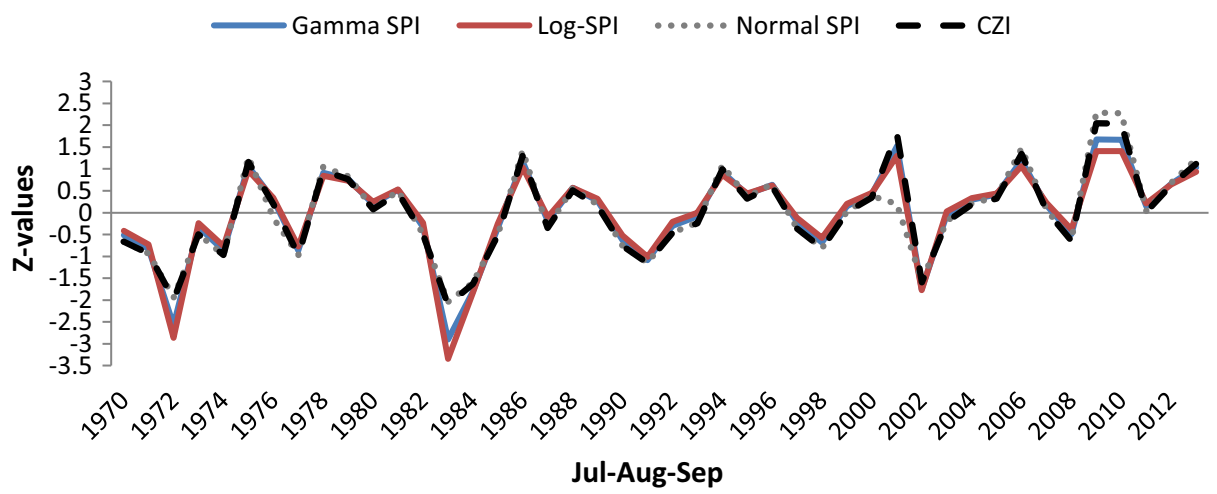

Fig. 14 SPI and CZI results for 3-months period for Rosso (Station 3) 


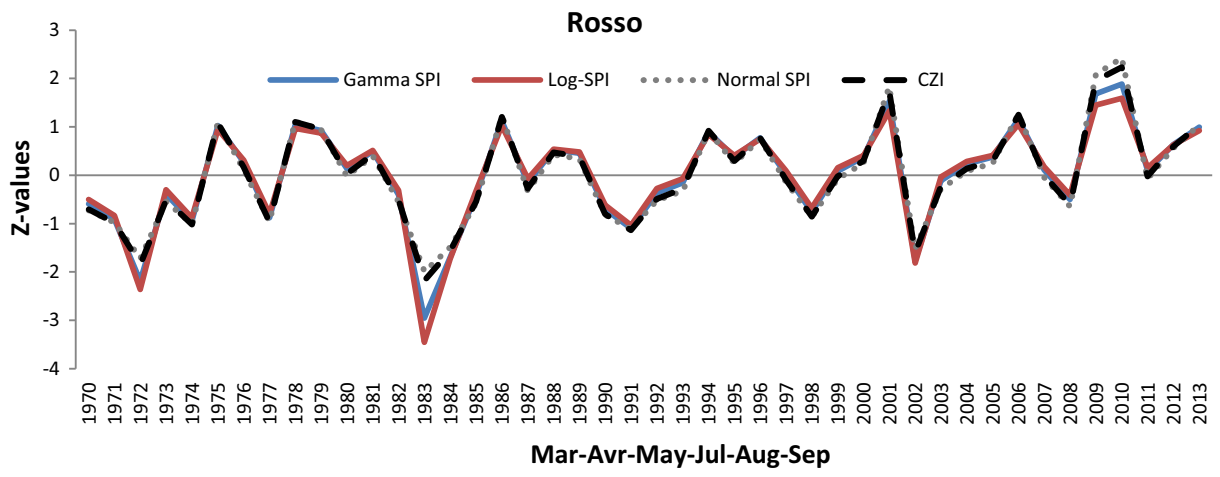

Fig. 15 SPI and CZI results for 6-months period for Rosso (Station 3)

The results in Tables 9 and 11 show that the drought is detected in the seventies and eighties more than the 1990s. Drought has less frequency in the 2000s, where it appeared at a rate of 1 in 10 years in the region. In 2010s the drought was seen again in 2011 (detected in station 1 by all methods). According to the PN results Table 10, Trarza region has experienced drought for 3 years consecutively from 1982, 1983 and 1984, which is considered the worse period for the region.

In Mauritania, recorded long droughts in 1910s, the 1940s, the 1960s, 1970s and 1980s have had dramatic environmental and societal effects, such as famine and dislocation (https://en.wikipedia.org/wiki/Sahel_drought). As seen in Table 9, for all the stations, PN, Deciles, the log-SPI and the gamma-SPI were able to capture these (early 1970s and early 1980s) extreme drought periods successfully. This result implies that these methods can be employed for drought analysis in this region.

\section{Conclusions}

This study investigated the performances of 6 DI methods for assessing drought in the Trarza region in Mauritania. The following conclusions are drawn:

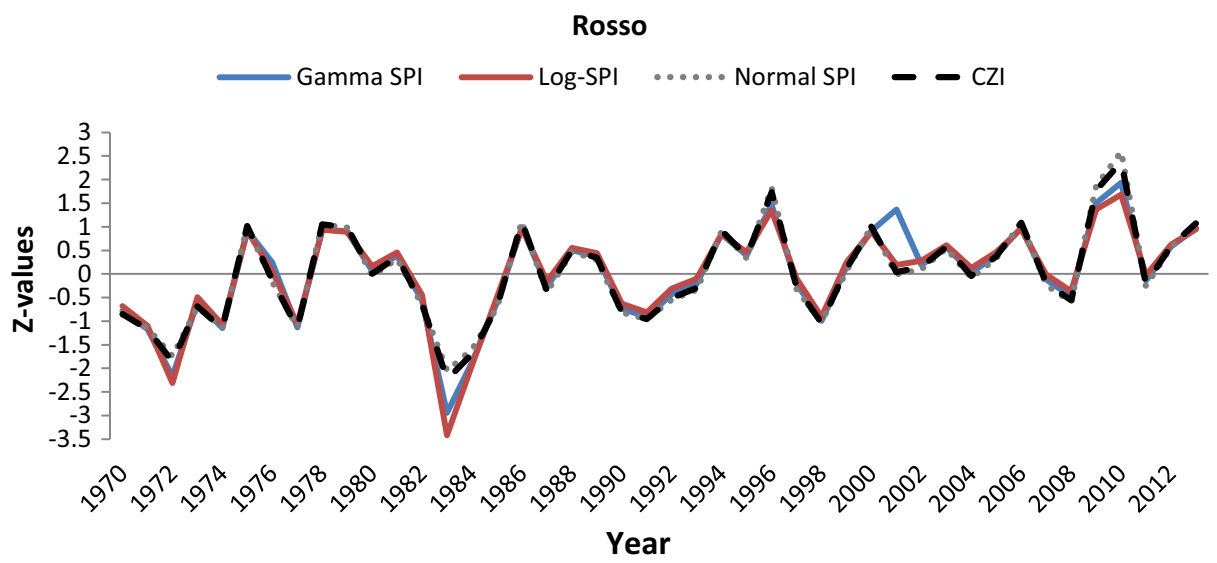

Fig. 16 SPI and CZI results for 12-months period for Rosso (Station 3) 
Table 8 Deciles result for Rosso (Station 3)

\begin{tabular}{ll}
\hline Annuals Rainfall values $(\mathrm{mm})$ & Classification \\
\hline $127.2-155.6$ & Much below normal \\
$177.9-204.5$ & Below normal \\
$234.8-264.0$ & Near normal \\
$285.2-328.8$ & Above normal \\
$338.3-477.8$ & Much above normal \\
\hline
\end{tabular}

1. DIs produced almost the same results for the drought analysis within the Trarza region.

2. Trarza region had experienced prolonged and severe drought during the periods of 1970 to 1974 and 1982 to 1985.

3. More droughts are detected in the seventies and eighties than in 1990s.

4. Twelve drought years might be experienced in station 2 and six in stations 1 and 3 in every 44 years. In other words, Nouakchott station can experience drought in every 4 years, while the other stations can experience it in every 7 years.

5. When the rainfall is less than $123 \mathrm{~mm} /$ year, $63 \mathrm{~mm} /$ year, and $205 \mathrm{~mm} /$ year, it is likely that severe drought would occur in Boutilimit, Nouakchott, and Rosso stations, respectively.

6. In the monthly period drought analysis; the CZI and the gamma-SPI methods makes similar predictions and the log-SPI makes extreme drought predictions for all the stations.

Table 9 Characteristics of Historical Droughts as detected by PN, Gamma-SPI, Log-SPI, CZI, Normal-SPI and Deciles

\begin{tabular}{|c|c|c|c|c|}
\hline Methods & $\begin{array}{l}\text { Drought } \\
\text { Intensity }\end{array}$ & $\begin{array}{l}\text { Station1 } \\
\text { (Boutilimit) }\end{array}$ & Station2 (Nouakchott) & $\begin{array}{l}\text { Station3 } \\
\text { (Rosso) }\end{array}$ \\
\hline & Extreme & 1987 & $\begin{array}{l}1971 \\
1977 \\
1983 \\
1984 \\
2007\end{array}$ & 1983 \\
\hline \multirow[t]{2}{*}{$\mathrm{PN}$} & Severe & $\begin{array}{l}1972 \\
1973 \\
1977 \\
1984 \\
2011\end{array}$ & $\begin{array}{l}1992 \\
2004\end{array}$ & $\begin{array}{l}1972 \\
1984\end{array}$ \\
\hline & Moderate & $\begin{array}{l}1971 \\
1981 \\
1982 \\
1983 \\
1988 \\
1990 \\
1997 \\
2004\end{array}$ & $\begin{array}{l}1970 \\
1974 \\
1978 \\
1980 \\
1982 \\
1985 \\
1986 \\
1987 \\
1994 \\
1997 \\
2002 \\
2003 \\
2006 \\
2008 \\
2012\end{array}$ & $\begin{array}{l}1970 \\
1971 \\
1973 \\
1974 \\
1977 \\
1982 \\
1985 \\
1990 \\
1992 \\
1997 \\
1998 \\
2008\end{array}$ \\
\hline
\end{tabular}


Table 9 (continued)

\begin{tabular}{|c|c|c|c|c|}
\hline Methods & $\begin{array}{l}\text { Drought } \\
\text { Intensity }\end{array}$ & $\begin{array}{l}\text { Station1 } \\
\text { (Boutilimit) }\end{array}$ & Station2 (Nouakchott) & $\begin{array}{l}\text { Station3 } \\
\text { (Rosso) }\end{array}$ \\
\hline & Extreme & 1987 & $\begin{array}{l}1977 \\
1983 \\
1984\end{array}$ & $\begin{array}{l}1983 \\
1972\end{array}$ \\
\hline \multirow[t]{3}{*}{$\begin{array}{l}\text { Log-SPI, } \\
\text { Gamma-SPI }\end{array}$} & Severe & $\begin{array}{l}1972 \\
1973 \\
1977 \\
1984 \\
2011\end{array}$ & 197120042007 & 1984 \\
\hline & Moderate & $\begin{array}{l}1981 \\
1983\end{array}$ & $\begin{array}{l}1974 \\
1978 \\
1982 \\
1985 \\
1992 \\
1994\end{array}$ & $\begin{array}{c}19711974 \\
1977\end{array}$ \\
\hline & Extreme & $\ldots \ldots \ldots$ & $\ldots \ldots \ldots$ & 1983 \\
\hline \multirow[t]{2}{*}{ Normal-SPI, CZI } & Severe & 1987 & $\ldots \ldots \ldots \ldots$ & $\begin{array}{l}1972 \\
1984\end{array}$ \\
\hline & Moderate & $\begin{array}{l}1972 \\
1973 \\
1977 \\
1981 \\
1983 \\
1984 \\
2011\end{array}$ & 197119771983198420042007 & $\begin{array}{l}1971 \\
1974 \\
1977 \\
1998\end{array}$ \\
\hline Deciles & $\begin{array}{l}\text { Extreme and } \\
\text { Severe }\end{array}$ & $\begin{array}{l}1970 \\
1972 \\
1973 \\
1977 \\
1981 \\
1983 \\
1987 \\
2011\end{array}$ & $\begin{array}{l}197119741977198319841992 \\
20042007\end{array}$ & $\begin{array}{l}1970 \\
1971 \\
1972 \\
1974 \\
1977 \\
1983 \\
1984 \\
1991 \\
1998\end{array}$ \\
\hline
\end{tabular}

7. In the 3-, 6-, and 12-month period drought analysis; the log-SPI and the gamma-SPI produce similar results, predicting more severe drought conditions while the normal-SPI and the CZI methods predict more wet case and fewer drought cases, for all the stations.

8. PN method tends to make fewer severe but more moderate drought conditions,

Table 10 The probability of drought recurrence by Gamma-SPI and log-SPI

\begin{tabular}{llll}
\hline Station & category & Number of times on 44 years & Severity of event \\
\hline 1 & Moderate drought & 2 & 1 in 22 years \\
& Severe drought & 5 & 5 in 44 years \\
2 & Extremely drought & 1 & 1 in 44 years \\
& Moderate drought & 6 & 6 in 44 years \\
& Severe drought & 3 & 3 in 44 years \\
3 & Extremely drought & 3 & 3 in 44 years \\
& Moderate drought & 3 & 3 in 44 years \\
& Severe drought & 1 & 1 in 44 years \\
& Extremely drought & 2 & 1 in 22 years \\
\hline
\end{tabular}


Table 11 The relations between the stations by PN

\begin{tabular}{|c|c|c|c|c|}
\hline Stations & $1,2,3$ & 1,2 & 1,3 & 2,3 \\
\hline Common drought years & $\begin{array}{l}1971 \\
1982 \\
1983 \\
1984 \\
1997\end{array}$ & $\begin{array}{l}1971 \\
1977 \\
1982 \\
1983 \\
1984 \\
1987 \\
1997 \\
2004\end{array}$ & $\begin{array}{l}1971 \\
1972 \\
1973 \\
1982 \\
1983 \\
1984 \\
1990 \\
1997\end{array}$ & $\begin{array}{l}1970 \\
1971 \\
1974 \\
1982 \\
1983 \\
1984 \\
1985 \\
1992 \\
1997 \\
2008\end{array}$ \\
\hline
\end{tabular}

9. Deciles, PN, the log-SPI and the gamma-SPI were able to capture historical extreme and severe drought periods (1970s and 1980s) successfully. This result implies that these methods can be employed for drought analysis in this region.

The water resources in Trarza are consists of groundwater and surface water. The source of the groundwater is the Trarza aquifer covering about $40,000 \mathrm{~km}^{2}$. This aquifer plays a very important role as the main ground source of water for Mauritania. The Senegal River is Mauritania's only permanent waterway which is used for irrigation, navigation, drinking, and hydro power generation. The water resources in Trarza region support a range of use including urban water supply and agricultural not only in the region but also in the surrounded regions in Mauritania. Thus, the assessment and monitoring of drought in this region is crucial for Mauritania.

\section{References}

Abramowitz M, Stegun IA (1965) Handbook of math functions. NBS Appl Math Ser 50:487

Alley WM (1984) The Palmer drought severity index: limitations and assumptions. J Clim Appl Meteorol 23 : 1100-1109

Asikoglu OL, Ciftlik D (2015) Recent rainfall trends in the Aegean region of Turkey. J Hydrometeorol 16(4): 1873-1885. doi:10.1175/JHM-D-15-0001.1

Barua S, Ng A, Perera B (2010) Comparative evaluation of drought indexes: case study on the yarra river catchment in Australia. J Water Resour Plan Manag 137:215-226

Cacciamani C, Morgillo A, Marchesi S. Pavan V (2007) Monitoring and forecasting drought on a regional scale: Emilia-Romagna region. Methods and tools for drought analysis and management. Springer

Edwards DC (1997) Characteristics of 20th century drought in the United States at multiple time scales. DTIC Document

Gąsiorek E, Musiał E (2015) Evaluation of the precision of standardized precipitation index (SPI) based on years 1954-1995 in ŁÓDŹ. J Ecol Eng 16:49-53

Gibbs Maher WJ (1915-1967) Rainfall deciles as drought indicators / by W. J. Gibbs and J. V. Maher., Melbourne : Bureau of Meteorology, 1967., Gibbs and Maher.

Guttman NB (1999) Accepting the standardized precipitation index: A calculation algorithm1. Wiley Online Library

Hayes M (2003) Drought indices. National Drought Mitigation Center. http://www.drought.unl. edu/whatis/indices.htm. Accessed 27 May 2003

Hayes MJ (2006) What is drought? Drought indices. National Drought Mitigation

Hayes MJ (2006) Drought indices, Wiley Online Library. Center. (Online).< http://drought.unl. edu/whatis/indices.htm 
HAYES MJ, SVOBODA MD, WILHITE DA, VANYARKHO OV (1999) Monitoring the 1996 drought using the standardized precipitation index. Bull Am Meteorol Soc 80:429-438

Ju X, Yang X, Chen L-J, Wang Y (1997) Research on determination of station indexes and division of regional flood/drought grades in China. QJ Appl Meteorol 8:26-32

Keyantash J, Dracup JA (2002) The quantification of drought: an evaluation of drought indices. Bull Am Meteorol Soc 83:1167

Lloyd-Hughes B, Saunders MA (2002) A drought climatology for Europe. Int J Climatol 22:1571-1592

Madsen H, Mikkelsen PS, Rosbjerg D, Harremoës P (1998) Estimation of regional intensity-duration-frequency curves for extreme precipitation. Water Sci Technol 37:29-36

Mckee TB, Doesken NJ Kleist J (1993) The relationship of drought frequency and duration to time scales. Proceedings of the 8th Conference on Applied Climatology, 1993. American Meteorological Society Boston, MA, USA, 179-183

MISHRA AK, SINGH VP (2010) A review of drought concepts. J Hydrol 391:202-216

MORID S, SMAKHTIN V, MOGHADDASI M (2006) Comparison of seven meteorological indices for drought monitoring in Iran. Int J Climatol 26:971-985

Palmer WC (1965) Meteorological drought. US Department of Commerce, Weather Bureau, Washington, DC

SONMEZ FK, KOMUSCU AU, ERKAN A, TURGUT E (2005) An analysis of spatial and temporal dimension of drought vulnerability in Turkey using the standardized precipitation index. Nat Hazards 35:243-264

Spinage C (2012) African ecology: benchmarks and historical perspectives, Springer Science \& Business Media

Thom HCS (1966) Some methods of climatological analysis. WMO Technical Note Number 81. Secretariat of the World Meteorological Organization: Geneva, Switzerland, p 53

Todorovic P Woolhiser D (1976) Stochastic Structures of the Local Pattern of Precipitation. Stochastic Approaches to Water Resources, 2

Tsakiris G, Pangalou D, Vangelis H (2007) Regional drought assessment based on the reconnaissance drought index (RDI). Water Resour Manag 21:821-833

Wilhite DA (1996) A methodology for drought preparedness. Nat Hazards 13:229-252

Wilhite DA (2000) Drought as a natural hazard: concepts and definitions. In: Wilhite DA (ed) Drought: a global assessment. Routledge, London, pp 3-18

Wu H, Hayes MJ, Weiss A, Hu Q (2001) An evaluation of the Standardized Precipitation Index, the China-Z Index and the statistical Z-Score. Int J Climatol 21:745-758

Yuan W-P, Zhou G-S (2004). Comparision between standardized precipitation index and Z index in China. J Plant Ecol 28(4):523-529. (in Chinese)

Zeng N (2003) Drought in the Sahel. Science 302:999-1000 